\title{
Chinese Students' Attitudes towards the Use of English-medium Instruction into the Curriculum Courses: A Case Study of a National Key University in Beijing
}

\author{
Abdulghani Muthanna ${ }^{1}$, Pei Miao ${ }^{2}$ \\ ${ }^{1}$ Institute for International and Comparative Education, Educational Leadership and Policy, Beijing Normal University, \\ Beijing, 100875, China \\ ${ }^{2}$ Key Institute of Humanity and Social Science, MOE; Center for Teacher Education Research of Beijing Normal \\ University, Beijing, 100875, China
}

Correspondence: Pei Miao, Beijing Normal University, Beijing, 100875, China

Received: June 3, 2015 Accepted: June 16, 2015 Online Published: June 30, 2015

doi:10.11114/jets.v3i5.920 URL: http://dx.doi.org/10.11114/jets.v3i5.920

\begin{abstract}
This article outlines the necessity for investigating the attitudes of local students towards the use of the English-medium instruction (EMI) strategy in their programs in China. It starts by presenting an overview of English as a global language, how English is emphasized in China, and briefly presents the concept of 'Attitude' and how the motivation factor plays a significant role in the conception processing of attitudes. Semi-structured interviews with six graduate students majoring in different programs are conducted. The analysis of the interviews identified that the participants hold very positive attitudes towards the use of the EMI strategy at their current programs. The participants, furthermore, expressed their complete readiness to join post-graduate programs wherein only the EMI strategy is implemented. In addition to the factors identified in the literature, the current article also recognized new factors that led the participants to conceiving positive attitudes: maintaining a global friendship, obtaining a leadership position, and acquainting with international scholars. Moreover, it is argued that 'quantity' precedes 'quality' in higher education institutions. Finally, the article provides a suggestion for how to meet the students' language needs and maximize the competition in obtaining top world-class university rankings.
\end{abstract}

Keywords: English-medium Instruction (EMI), students' attitudes, Chinese Higher education

\section{Research Background}

As an international language, English is the language of scientific communication in multilingual contexts (Galloway, 2013), considered as "a symbol of modernization" (Kachru, 1985, p. 16), used as a medium of instruction in many universities worldwide particularly in non-native speaking countries with a vision for future access to the scientific and technological progress in the developed countries (Surur, 1981), and to further education overseas and careers in governments (Evan, 1999; Liu \& Zhao, 2011). It is also used for peacekeeping among nations through specialized English language training offered by UK in the form of Peacekeeping English Project (PEP) that provides training and English for Specific (ESP) materials for international military forces (Crossey, 2008). All these factors have led English to then become an international language. Non-native speakers of English outnumber the native speakers (Kaur, 2014) and therefore, it is safe to note that English has become the language of all those who speak it. In the recent past, there has been an emphasis on the use of English as a Lingua Franca in teaching contexts (Seidlhofer, 2004); however, the recent emergence of the 'global Englishes' concept as a new field combines both 'global Englishes' and English as a 'lingua franca' (Galloway, 2013) or as an intercultural communication mode among speakers of non-English speakers (Jenkins, Cogo, \& Dewey, 2011). English has also become a necessary tool for global higher education institutions to compete with one another and promote more internationalization by accommodating both international and domestic students who use English as a medium of instruction (Chen \& Kraklow, 2014). To phrase it differently, the use of English-medium instruction has become a strategy adopted by universities to compete in a much globalized world for promoting their profiles (Altbach \& Knight, 2007) and to prepare local students who meet the demands of the global markets (Doiz, Lasagabaster, \& Sierra, 2011). 
As a competent in the world economy (markets), China needs to further cultivate citizens who can communicate in this international language (English) easily to further compete in the global economy (Zheng, Young, Brewer, \& Wagner, 2009). This global economy competition involvement encourages China towards putting a stronger emphasis on English education administered by the Ministry of Education at primary and secondary schools (Ministry of Education, 2001). Even before entering universities, students must take the entrance exam known as Gaokao in which English is tested as a main subject. Furthermore, two standardized national English proficiency tests are administered at Chinese universities: 1) College English Test (CET), and 2) Test for English Majors (TEM). CET is designed to assess the ability of non-English major students to use English and is of two levels: Band 4 reflects an intermediate level, and Band 6 indicates upper intermediate level. All applicants are required to pass CET Band 4 before graduation (Ministry of Education, 2001). Moreover, English-medium instruction has also been adopted in several universities in China but it seemingly appears that they have been established for inviting international students only. Local students are not encouraged or required to register in such programs for some reasons that will be investigated in the next paper.

At the tertiary level, learning of English as undergraduate, graduate, or post-graduate language majors is offered in most of the universities in China. Research on English language major learners in China showed that learners positively view the learning of English as a major and are highly motivated to learn English (Liu, 2007a; Liu \& Zhao, 2011; Yang, Liu, \& Wu, 2010). Additionally, Yu (2010) reported that Chinese college students have positive attitudes towards English and their 'Chi-English' as an accent. Similarly, Zhang and Ding (2011) accentuated that Chinese students had no significant negative attitudes toward their Chinese accent while learning or speaking English. Resultantly, it is very acceptable that English has become the world language and it is the language of any speaker who can convey their ideas well.

On the contrary, Chinese non-English major students might have different attitudes towards learning English and this might differ from one province to another and from one university to another, too. Xu, Wang, and Case (2010) presented that multifaceted attitudes towards English exist and students' pragmatic needs (while learning English) should be well thought of and be addressed accordingly by instructors. For example, Liu and Laohawiriyanon (2013) investigated Chinese non-English major students' attitudes towards learning cultural themes of different countries in an anonymous university in China and showed that students preferred to learn themes concerning their own culture followed by themes of international target culture (English). This indicates how important to explore the attitudes and preferences of students so as to make the teaching-learning process more engaging and effective.

English as a Medium of Instruction (EMI) in Taiwan is employed in different universities with a switch code of Mandarin in the classrooms ( $\mathrm{Wu}, 2006)$. On the other hand, students in the mainland of China do not have more opportunities to use English in "authentic settings and generally have low self-efficacy and poor attitudes toward English language learning" (Zheng et al., 2009, p. 206). Therefore, this present study is very different from all mentioned above in many dimensions, some of which are the following. Firstly, it is the first study that aims to explore the attitudes of Chinese university learners majoring in different specialty areas other than English towards the use of English as medium of instruction in their programs. Secondly, the participants are graduate students at a Chinese university given the pseudonym of Heaven University to keep its anonymity and it is the first study in which graduate students' attitudes are investigated in China. Thirdly, it is the first study that employs a qualitative methodology with in-depth interviews. Finally, the findings of such a study provide implications for education policy-makers, especially language policy-makers at Chinese higher education institutions.

\section{Overview of Attitudes}

Attitude is a central issue in the field of psychology. Researchers have provided several definitions for this concept. For example, attitudes are ones' positive or negative reactions toward any aspect of social world (Fazio \& Roskos-Ewoldsen, 1994; Tesser \& Martin, 1996). According to Eagly and Chaiken (1993), attitude is "a psychological tendency that is expressed by evaluating a particular entity with some degree of favor or disfavor" (p. 1). More specifically, attitude is a construct used to explain consistent human behavior patterns (Baker, 1992). Fasold (1984) regarded attitude as either mentalistic or behavioristic. In other words, attitude is seen as a variable that intervenes between a stimulus and a response that affects people's behavior (Fasold, 1984). There are three components of attitude: 1. Cognitive attitude that is related to thoughts and beliefs, 2. Affective attitude that is associated with feelings, and 3. Behavioral (intentional) attitude that is concerned with events planning and doing in particular circumstances (Baker, 1992, p. 12). Moreover, Bloom (1995) pinpointed that "a meaningful correlation between the meanings of success of attitude is significantly important as cognitive behavior" (as cited in Hussein, Demirok, \& Uzunboylu, 2009, p. 432). The crux of all these definitions is that attitude is positive or negative and this is due to many factors: one's social background, geographical area, age, gender, and personal achievements are all factors that form one's beliefs that lead to showing one's attitude towards an object (Gardner \& Symthe, 1975a; Jones, 1950a). 
Attitudes on language are known as language attitudes (Fasold, 1984). Littlewood and Liu (1996) proposed three types of language attitudes: affective, socio-political, and pragmatic attitudes. These language attitudes types are centered on students' feelings towards a target language or culture (Pierson, 1987). These feelings are not arbitrarily obtained. They, nevertheless, have been got through social and schooling experiences. Language ability plays a crucial role in one's attitude towards a particular language. However, this language ability might be affected negatively if that student has negative attitudes toward that target language (Sze-yan, 2005, p. 3). There are factors that play a significant role in the formation of students' language attitudes: use of and familiarity with the target language, stereotypes, previous experiences, and future goals (Galloway, 2013, p. 795). The author, however, argues that the most important factor is 'motivation' as it is the trigger that forms the attitudes. Motivation is the concept that many researchers have studied for a long period. Generally, motivation is a "combination of effort plus desire to achieve the goal of learning the language plus favorable attitudes towards learning the language" (Gardner, 1985, p. 10). This definition seems to separate the concept of attitude from that of 'motivation'. Motivation is of three types: 1) Integrative motivation that describes students who have positive attitudes towards the community of L2 (Gardner, 1985); 2) Intrinsic motivation which is the engagement in an activity that is enjoyable to do (Noles, Pelletier, Clement, \& Vallerand, 2000), and 3) Extrinsic motivation that refers to actions done for the sake of reaching an instrumental end such as receiving a reward or avoiding a punishment (Noles et al., 2000, p. 61). Motivation could be positive or negative and, as a result, the attitude would also be either positive or negative. However, the degree of motivation and how it is given or perceived can also change the attitude. In brief, motivation plays a high significant role in the process of conceiving and perceiving attitudes.

This paper focuses on the affective attitudes of graduate students towards the use of the English-medium instruction strategy in their graduate programs. In other words, this affective dimension is related to finding out whether students like or dislike the use of English as a medium of instruction in their programs and the reasons behind their feelings/preferences. Meanwhile, the paper sheds light on the pragmatic dimension that deals with the usefulness or uselessness of using English as a medium of instruction, which has been argued in the introduction.

\section{Research Design}

In this qualitative case study, the authors focused on one national key university in Beijing, given the pseudonym of Heaven University. The authors intended to adopt such an approach for it is a suitable and flexible inquiry for studying a specific issue within its natural context (Yin, 2003). Further, within this qualitative case study, the authors specifically adopted the Instrumental case study that "provides insight into a specific theme or issue" (Mcmillan \& Schumacher, 2010, p. 345).

Both authors designed the semi-structured interview questions with a focus on addressing these two central questions: 1 . what are the attitudes of Chinese non-English major graduate students towards the use of the English-medium instruction strategy in their programs? and 2. Why do Chinese non-English major graduate students hold such attitudes? The primary author conducted the interviews (audio-recorded) with six students of master's degree programs. The length of each interview ranges between 70 and 90 minutes. Each interviewee was interviewed individually in English. Selection of students was based on criterion sampling as the authors focused on including a participant from a different program. This technique increases the chance of finding out different attitudes towards the issue under study. The participants voluntarily participated in the study and a consent form was obtained before conducting the interviews. Following is a profile of the study participants

Table 1. Study Participants' Profiles

\begin{tabular}{llll}
\hline Participants Codes & Gender & Age & Study Program \\
\hline Participant 1 & Female & 24 & Educational Technology \\
Participant 2 & Female & 25 & $\begin{array}{l}\text { Technical and Vocational } \\
\text { Education }\end{array}$ \\
Participant 3 & Male & 25 & Educational Law \\
Participant 4 & Female & 27 & Sociology of Education \\
Participant 5 & Female & 24 & Teacher Education \\
Participant 6 & Male & 28 & Teacher Education
\end{tabular}

Although this study is limited to the inclusion of a few participants, the authors believe that having only six participants helped in systematically collecting data and in depth. After transcribing the data using the verbatim technique (firstly by the primary author), each participant's data was profiled individually. The second author checked the transcriptions carefully again, which realized the peer-review technique. Each profile contains between 5000 and 6500 words as data. 
The presence of a few participants was also very effective in the process of systemic analyses by transcription, intensive reading, and interpretation and reflection analyses of data (Gall, Gall, \& Borg, 2003). This also supports the argument that no matter whether small or big the research sample is, or what researchers' interests are, as the main purpose is to collect data systematically (Mintzberg, 1979). Following is a presentation of the study findings.

\section{Findings and Discussion}

The data analysis led to the emergence of several patterns reflecting the attitudes of the graduate students towards the use of English as a medium of instruction in their programs. The themes also pinpoint the factors that led the participants to possessing/conceiving such attitudes and how to meet the language needs of students. Here are the main patterns.

\subsection{Students' Positive Attitudes to EMI: Preference and Readiness}

There is no dispute about the state of English as an international language and its use as a medium of instruction in many universities worldwide. For example, universities across Europe adopt English as a medium of instructions in undergraduate and graduate programs while in Stockholm University both English and Swedish are used in parallel (Bolton \& Kuteeva, 2012). In many other non-English countries, there are many universities using English as a medium of instructions for many programs. Such universities require students to prove their English proficiency through submitting certain certificates of Toefl, IELTS, etc. A perfect example where all programs are instructed in English is Middle East Technical University, Ankara, Turkey.

Benson (1991) considered English useful for a selection of modern functions while it could also be regarded non-useful for local students. This assumption seems to be true in the case of Heaven University that houses hundreds of majors instructed in Chinese. Although all programs but eight ones at Heaven University are instructed in Chinese, the study participants preferred the existence of more English- medium instructed programs so that students can have the choice to enroll in the program they prefer although they are not allowed to register in such programs. They also expressed their readiness to join the English-medium instructed programs in their post-graduate studies. Participant 1 expressed her attitude by saying:

I'll be very happy to join a post-graduate program in English. I will also advise my friends to join programs where teachers use English in teaching ... because I am currently engaged in reading books, articles, etc. in English as requirements for some of my courses that [laughter] instructed in Chinese despite the actuality instructors can use English.... I guess I spend one third of my time for reading English materials.... I am fully aware that English is important in my field and I'm fully ready to spend all time in reading English materials and not mixing [Chinese and English] that distracts my attention here and there!

The authors' analysis to the above discourse of participant 1 indicates that she prefers to be instructed in English in her current program. Instead of being instructed in Chinese inside the class while English is used mostly outside the class for research purposes, searching and reading reference specifically, the participant expresses her ultimate preference towards a program fully instructed in English. The discourse also implies that the participant suggests a new policy for her current program to adopt the English-medium instruction strategy so long as most of the instructors are capable of teaching the courses in English. Similarly, participant 2 expressed that she spent most of her time in finding and reading English publications and then uses the translation process to convey ideas in the Chinese language. She said:

I need English as I am in need to read materials written in English about my major and to get good knowledge, I must read them.... Then I make translations into my language and use them in my papers or projects. This is troubling: the translations take lots of my time and it is better for me to be taught in English and write the assignments in English without the burden of translation!

This above discourse shows that it is not a translation major where students are trained on the processes of translation through more practice. Participant 2 seems to be unhappy that she spends most of her time in translating from English into Chinese. The discourse also suggests that the policy-makers of that program need to rethink of the curriculum and the courses requirements and how to meet the needs of their students. The authors analyze the discourse of participant 2 as an indicator for the absence of evaluation of students' needs, an assessment that is important in any educational institution. Similarly, participant 3 also reflected his attitudes towards the English-medium instruction strategy by noting that:

It is better to use English in the classrooms. English is important for all of us and that is why we must undergo English tests from primary schools until we become professors... Policy makers know this reality but they do not give us any option. I prefer to do my studies in English.... I'm ready and must study in English in future even if abroad.

This statement indicates that participant 3 is willing to pursue his post-graduate studies in English within the borders of his country providing that education policy-makers rethink how to change the medium of instruction of his program. The statement also shows that English is very important in the educational contexts in China as it is highlighted in all 
educational stages. As a result, it is suggested that, instead of compelling students to travel abroad for achieving their language-medium instruction needs, education language policy-makers are recommended to implement the English-medium instruction strategy for many programs at their universities in addition to the existing English-medium instruction programs that have invited hundreds of international students.

In short, although Chinese graduate students are allowed to take English instructed courses from other programs, they are not encouraged or required to join any English-instructed program at all. This might be related to policy-makers' awareness of certain issues such as cultural loss, colonization, etc. Despite these challenges students face, the authors contend that the participants have expressed their preferences of selecting English as a medium of instruction for their current and future studies. They also expressed their readiness to continue their studies in programs wherein the English-medium instruction strategy is implemented. The informants also referred to traveling abroad in case their needs are not met in their own country. Instead of caring for the needs of international students only, language policy-makers also need to concern themselves with the needs of their local students who will really care of the development of their country better than any others. The authors are aware of the challenges of implementing this language policy for many programs at all universities and how policy-makers might think of the issue of cultural identity loss; however, the authors suggest that they consider allowing local students to enroll in the existing EMI programs or establishing a whole university where all majors exist and are instructed in English. This university will meet the needs of such local students and achieve a top world-class university ranking as well.

\subsection{Multiple and Additional Factors behind Attitudes: Academic Network; Global Friendship; \& Leadership Position}

Factors behind the presence of students' positive attitudes towards the importance of establishing several English-medium instruction programs are much related to academic purposes. All informants expressed their need for the English language for achieving academic readings and writings. They emphasized the point that English is a key language in scientific communication and how it is very significant in their current studies and future identities. In addition to the factors behind the existence of positive attitudes identified in the literature, the authors' analysis has also led to the emergence of new factors that are briefly descried in the following sub-themes.

\subsubsection{Academic Network: Self-identification as International Researchers}

As china has the largest population in the world, it is then anticipated that China possesses the largest number of students learning English since English is taught at the primary stages of learning. Day by day, English in China is getting more significance. The use of English names by almost all Chinese higher education students is a clear indicator that English is warmly welcomed in China. Students do not use any other language names but English although Wu (2012) explained that such representation is confusing as important features of the Chinese language are lost. This is a one way of attracting attention and for facilitating the communication process between them and international scholars, though.

Keeping in touch with international scholars has become necessary these days. This is very much highlighted in the academia where all academics and/or researchers are supposed to acquaint with one another especially those who have the same research interests. This academic network facilitates the fast dissemination of knowledge and underscores a better understanding of phenomena studied by several different scholars while corresponding with one other. The participants of this study have pointed out to such a factor of 'academic network' as an essential reason for their positive attitudes towards learning English in general and using English as a medium of instruction in current and future programs in particular. For instance, participant 1 discoursed that:

I think English is important in any academician's life ... it is necessary for reading international papers in our field.

When I want to write a review paper, I must look for papers and books written in English language ... English is also important for my future career ... I am looking for a teaching career at university ... universities, as you know, require instructors to publish papers in high-impact journals. So, I need to master English and I wish to be instructed wholly in English.

The above discourse is encouraging in the view that the participant looks forward to becoming a university instructor and an international researcher who anticipates publishing good articles in high-ranking journals. The discourse also reveals the truth that higher education institutions are competing with one another through publishing in high-impact journals for the sake of promoting the profiles of their universities while some professors might publish for the sake of surviving in the academic positions, receiving funding and salary increment (Feng, Gulbahar, \& Dawang, 2013; Lee \& Lee, 2013). This also highlights the saying of the primary author's father: 'write or hide' which means that it is necessary to publish papers so as to gain recognition among colleagues within the institution and colleagues in the field as well. In line with the attitude of participant 1, participants 2 and 3 also expressed similar attitudes behind their positive preference of using English as a medium of instruction. They said:

... I enjoy using it [English] more than my native language. This is because I spend most of my home studies in

English and writing reflection/synthesis papers which I translate into my mother tongue for the courses 
requirements... I want to do my post graduate studies in a western country where I will be instructed in English ... But if my university provides this option for me, I will stay here and join the program. (Participant 2) For me English is important to keep in touch with anything new in this small world. To have more knowledge about any issue, English is the language that provides lots of references.... Most of international scholars write in English especially those whose first language is not English.... (Participant 3)

The authors interpret the statements of both participant 2 and participant 3 as strong indicators of the importance of English as a main link between international scholars whose first languages are naturally different from English. Within the statement of participant 2, it is safe to note that there is a call for providing more options for students in terms of language-medium instructions, an action that will help local students to pursue their higher studies within the borders of China. Furthermore, it appears that the participant is not content with the current language policy where they spend lots of time for translations from English into Chinese. Instead, they prefer to use English without any efforts in translating texts and this might ease the process of learning for such students. Another safer note to make is stated by participant 3 that English is probably the most prominent language that can offer deeper insights to any issue around the globe; this is due to the matter that most publications are in English these days, specifically high-ranking publications.

These findings are supportive to the findings of several researchers who stated that English has become necessary for scientific research, future studies, technological progress, improvement of universities profiles, and often jobs in today's globalized markets (Altbach \& Knight, 2007; Doiz, Lasagabaster, \& Sierra, 2011; Evan, 1999; Galloway, 2013; Liu \& Zhao, 2011; Matsuda, 2013; Surur, 1981). To conclude, the policy makers might need to allow local students to enroll in the existing EMI programs and establish more English-medium instruction programs. Otherwise, they might benefit of the suggestion that advises the incorporation of courses that intensively train students on academic writing and writing for publication purposes in the current programs (Martin, Rey-Rocha, Burges, \& Moreno, 2014).

\subsubsection{Global Friendship}

Global friendship is an interesting theme as it indicates the importance of attracting acquaintances from the whole globe. It is very beneficial to have acquaintances from different parts of the world. This friendship increases one's criticality towards one's own behaviors and thoughts together with these of others. It also helps graduate students to build stronger sensitivity which is significant for all researchers. There are many issues in this world where researchers should be very sensitive while discussing or reporting and this global friendship process is one of few key transparent tools for increasing direct and indirect awareness towards sensitive issues especially in international contexts.

The father of the primary author once articulated that "it is good to have a palace in each country" and 'a palace' here means friend. It is safe and interesting to compare a friend to a palace where true friendship exists. Students within or outside their schools' precincts need to make friends that become part of their lives. In international educational settings, hundreds of students exist and the common language they speak is English. English is the main link that can make all of them communicate and understand one another very well. English, according to the study participants, is the main language for making global friends. Here are their discourses on this interesting theme:

If I want to speak to any stranger at this university or another, I use, speak English. Once upon a time, I tried to use another language but no answer, no attention. English is good to make friends from other places. (Participant 4)

No English; no international friends. A lot of international students are in our university and many do not speak good Chinese. Understanding each other, we use English. If you do not speak English ... your English is weak, they [become] bored and do not want to talk [to] you another time. (Participant 5)

I need English for corresponding with my international friends, for making new ones, and for making it easy for me to live with this world where English is dominant in many sciences. (Participant 6)

The authors analyze these above three discourses as an important indicator of students' positive attitudes towards learning good English. It is to have 'global friendship'. Global friendship inside and outside higher education institutions depends, according to the study participants, on the use of English. For many international students, English is the mode of communication and therefore attracting their friendship demands one to learn and speak good English. The discourses of participant $4 \& 5$ also show that a good command of English is needed so as to build good and quick friendship with international students who would then become critical friends at later stages. A critical friend is the one who works like a mirror by whom one can see one's positives and negatives. This critical friendship is significant for international students who aspire to be university instructors or researchers as it motivates them to reflect upon one another for better and quicker development.

To conclude, it is safe to note that students in international educational settings are supposed to make international friends as it might be a way to increase knowledge about global issues through the communication that might occur between them. However and according to the participants, it is not easy to make global friends when a local student does not speak or uses poor English. 


\subsubsection{Leadership Positions}

Leadership is an activity that demands leaders to acquire lots of skills through either practice or mentoring. Skills such as being critical, creative, flexible, and many behavioral qualities will enable leaders to be strategically focused and achieve their roles as quickly and effectively as possible. In all settings, leaders must be very patient, have strong visions, and capable of dealing with different issues logically and systemically. Further, they need to have a very good spirit of teaming with local and international people/employees and be able to build a strong trust among one another. In educational settings in particular, the activity of leadership is more complex as educational leaders deal with complex, different types of personalities that demand varying skills and systemic thinking/planning. In reality, getting a leadership position is not easy these days since it undergoes several requirements. So far as educational leaders need to contact with different stakeholders who might have different languages (specifically in international educational settings), it is expected from effective educational leaders to speak English that facilitates a better and easier communication with all stakeholders, particularly teachers and students. English has become a requirement for promotion in jobs and an essential factor in obtaining a leadership role in many settings. In this concern, the participants of this study discoursed the following:

I knew a school principal who did not speak English; he was suffering very much while interacting with international students. Although he is old but he decided to learn English (Participant 4).

Many leaders in this world speak English. A leader might need to communicate with other leaders in an international setting, so she or he should speak English. If not, no communication happens and will lose this opportunity (Participant 5).

Many leadership positions advertised in these days clearly require good English. So if you are not good in English, you won't have this opportunity. I learn English also to increase chances and get a better leadership role one day (Participant 6).

These above three discourses share one common theme related to obtaining a leadership position that, according to the participants, requires learning the English language. The shared story of participant 4 is interesting as it shows the challenges schools' leaders face while communicating with international students. It is safe to note that such situations are embarrassing as that school's principal decided to learn English even at an old age. In order not to face such an embarrassing situation, participant 4 is motivated to learn English and obtain a leadership position (possibly a school principal). The fifth participant similarly stated that it is embarrassing for leaders not to speak English where international leaders meet or when it is needed. This is an indicator that the participant is looking for a leadership position wherein international leaders get together and inspire one other. The statement of participant 5 shows that learning English will be very helpful for obtaining such positions. In the same vein, the discourse of participant 6 indicates that such positions of leadership advertised in jobs websites regard English as one of the main requirements. By developing such awareness of the importance of learning English, participant 6 believes that learning English will provide him with better options later while looking for leadership positions. To conclude, the analysis identifies obtaining 'a leadership position' to be one of the factors behind acquiring good English.

In conclusion, the authors note that the factors behind the students' attitudes towards adopting the English-medium instruction strategy re-enforce those found by previous researchers. In addition, the current study states that making and/or keeping a good relationship with global friends, obtaining a leadership position, and acquainting with international scholars (academic network) are also key factors in the presence of students' positive attitudes in adopting the English-medium instruction strategy in their current and future studies. All these factors, as the authors have argued, motivate such participants to conceive positive attitudes; therefore, positive motivation is the first step towards perceiving and conveying positive attitudes.

\subsection{Implications to the Policy: Quality Comes After Quantity}

It is true that quality is very important in all life dimensions; however, quantity is sometimes more important than quality especially in academic settings where there is a big gap between equity and equality issues. Almost all higher education institutions are craving for the improvement of quality issues in their programs as they have entered the endless arena of top world-class universities competition. It is argued that those current top universities have initially attained the concept of equity by providing equal access, opportunities, and treatment to all affiliates without making any discrimination among them. At later stages, they carefully started to consider the concept of equality through giving appropriate opportunities and supports to their affiliates according to the needs of those individuals.

Equity can be quantified while "true equality can never be quantified, because all men are truly different from each other" (Coates \& Topham, 1974, p. 250 as cited in Dunleavy, 1989, p. 214). Equality is the concept that can simply be defined as a quest for sameness in all social life aspects. It is concerned with the variability of individuals and how to improve these differences individually. Equity, on the other hand, deals with standardizing a public policy treatment of all individuals equally without considering the differences among these individuals (Dunleavy, 1989, p. 214). The 
participants of this study expressed that their university has made a great success in establishing many numbers of programs that can lead to achieving the issue of quantity and this is, according to them, an essential step towards a permanent success. Participant 1 expressed her viewpoint by saying:

In our university, there are lots of programs that specialize in different education and science areas ... we have several professors and educators in our program, for example, and this, according to my thinking, is a matter of quantity that is essential in academic life.

The above statement of participant 1 shows the participant's attitude towards the importance of providing equal opportunities for professors and students in joining different majors for teaching and learning respectively. The statement also pinpoints the author's assumption that quantity should precede quality in the educational contexts. Furthermore, participant 1 explained that "quality can't be attained when there is no quantity" which means that quality is subjected to the realization of achieving quantity in educational programs, at the outset. Similarly, participant 2 demonstrated her attitude by uttering the following discourse:

There are a great number of programs that are instructed in Chinese and only few ones instructed in English... and those taught in English seem to be established for inviting international students only. Our university is doing well but they [university policy makers and main implementers] need to consider establishing more programs for both international and national students at the same time.

This might be true as this above discourse focuses on both concepts of 'equality and equity' discussed above. The presence of an acceptable number of English-medium instruction programs, according to participant 2, is important as there might be many local students who prefer to join such programs. The presence of such English-medium instruction programs will not only lead to improvement in quantity of programs but also urge policy makers to reflect upon the development of those programs in terms of quality. On this theme, the third participant revealed his attitude by stating the following:

Less programs is a problem especially when these programs are founded without paying attention to local stakeholders [Chinese students] ... we, Chinese students, need to realize our hopes by attending the program we prefer and use the instruction medium we feel happy at. This is not happening in my university and many other universities in China. The Ministry of Education is looking for having top world-class universities ... they have established some majors instructed in English but they paid no attention to us or thought of giving us any choice to join the major where different instruction mediums are offered.

This above statement, as the authors interpret, is very crucial for education policy makers who need to reconsider the needs and preferences of their local students. The Chinese students might need to join programs that are taught in English and the policy makers need to respect these students' needs by realizing their views in reality. The above statement also suggests that attaining the needs of local students will also help attain the standards of top world-class universities for which the Chinese government has paid greater attention these recent years.

To conclude, the authors have argued that good quantity is the first step towards a better quality. The universities policy makers need to work on this new concept 'quality comes after quantity' and try to provide several programs wherein the English-medium instruction strategy is implemented. Voices of local students are critical for the development of local higher education institutions.

\section{Conclusions}

In this paper, the authors have presented the attitudes of Chinese non-English majors graduate students at Heaven University towards the use of the English-medium instruction strategy. The participants expressed their positive attitudes towards the use of the English-medium instruction strategy in their programs and highlighted the need for programs instructed in English not only for inviting international students but also for realizing the hopes and ambitions of local learners. They, furthermore, underscored the point that they prefer the English-medium instruction strategy in their current and future studies and unless policy makers re-consider students' attitudes, students would leave the country for realizing their personal needs and preferences. Therefore, the authors suggest the Ministry of Education in the People's Republic of China to implement this idea of allowing local students to enroll in the existing EMI programs and increase other EMI programs. Or they are recommended to establish a university that adopts all programs with the use of the English-medium instruction strategy. Local and international students are welcomed to this university so long as they meet the entry requirements. This university will certainly be one of the top universities in the world then.

The paper also outlined the need for studying the attitudes of local students and the factors behind their attitudes. Meanwhile, the paper presents a model that could be adopted for achieving the two important issues of 'equity and equality' in higher education institutions. 


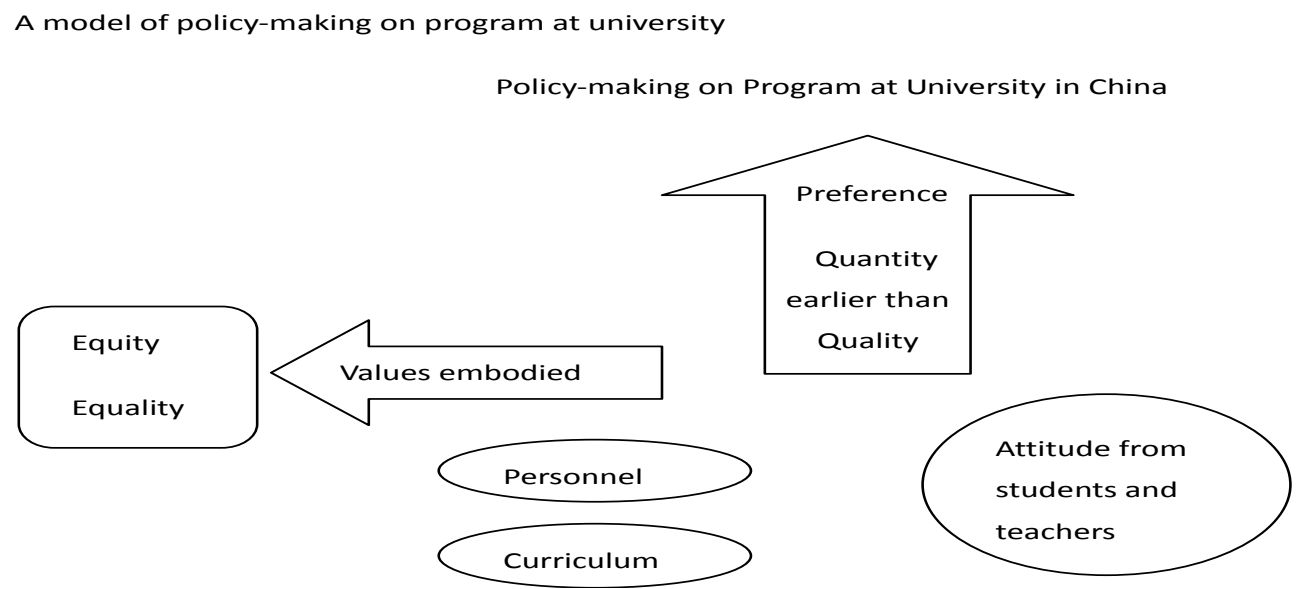

This model shows how equity and equality concepts can be realized at higher education institutions. In simplest words, the model suggests that higher education institution policy makers need to investigate the attitudes of their affiliates (both students and instructors) whose attitudes are based on the internal and much strongly on the external motivation. In other words, a needs analysis to students' and teachers' attitudes and preferences along with the curriculum would lead to a sound policy decision.

By motivating students positively, the students will conceive positive attitudes and critical awareness towards which programs they prefer and which medium of instruction they like. Considering the attitudes of students and teachers will also lead to rethinking of the number of programs instructed in that preferred language. Achieving this will also lead policy-makers to consider the most important issue of 'equality' that directly leads to the presence of good quality. Again, good quality will lead to having positive motivation in the hearts of students towards education and this will enforce the authors' idea that good inputs lead to good outputs. To conclude, the authors personally believe that the application of equity leads to the presence of true equality. And the existence of true equality leads to good quality. In other words, good quantity precedes good quality and the presence of both helps in achieving the standards of top world-class universities.

\section{References}

Altbach, P. G., \& Knight, J. (2007). The internalization of higher education: Motivations and realities. Journal of Studies in International Education, 11, 290-305. http://dx.doi.org/10.1177/1028315307303542

Baker, C. (1992). Attitudes and Language. Clevedon: Multilingual Matters Ltd.

Benson, M. J. (1991). Attitudes and motivation towards English: A survey of Japanese freshmen. RELC Journals, 22(1), 34-48. http://dx.doi.org/10.1177/003368829102200103

Bolton, K., \& Kuteeva, M. (2014). English as an academic language at a Swedish university: Parallel language use and the 'threat' of English. Journal of Multilingual and Multicultural Development, 33(5), 429-447. http://dx.doi.org/10.1080/01434632.2012.670241

Chen, Y. E., \& Kraklow, D. (2014). Taiwanese college students' motivation and engagement for English learning in the context of internalization at home: A comparison of students in EMI and non-EMI programs. Journal of studies in International Education, 1-19. http://dx.doi.org/10.1177/1028315314533607

Crossey, M. (2008). English for global peacekeeping. Current Issues for Language Planning, 9(2), 207-218. http://dx.doi.org/10.1080/14664200802139448

Doiz, A., Lasagabaster, D., \& Sierra, J. M. (2011). Internalization, multilingualism, and English-medium instruction. World Englishes, 30, 345-359. http://dx.doi.org/10.1111/j.1467-971X.2011.01718.x

Dunleavy, P. (1989). The concept of equality in policy analysis. Journal of Theoretical Politics, 1(2), 213-248. http://dx.doi.org/10.1177/0951692889001002005

Eagly, A. A., \& Chaiken, S. (1993). The Psychology of Attitudes. Orlands, FL: Harcourt.

Evan, S. (1999). The medium of instruction in the engineering steam at tertiary level in Hong Kong. Educational Journal, 27(2), 12-41. 
Fasold, R. (1984). The Sociolinguistics of Society. Oxford: Basil Blackwell.

Fazio, R. H., \& Roskos-Ewoldsen, D. R. (1994). Acting as we feel: When and how attitudes guide behavior. In Shavitt, S. \& Brock, T. C. (eds.) Persuasion. Boston: Allyn and Bacon, 71-93.

Feng, H., Gulbahar, H. B., \& Dawang, H. (2013). From 'import' to 'import-export' oriented internationalization; the impact of national policy on scholarly publication in China. Language Policy, 12, 251-272. http://dx.doi.org/10.1007/s10993-013-9285-8

Gall, M. D., Gall, J. P., \& Borg, W. R. (2003). Educational research: An introduction. (7 ${ }^{\text {th }}$ Ed.). Boston: New York.

Galloway, N. (2013). Global Englishes and English language teaching (ELT)- Bridging the gap between theory and practice in a Japanese context. System, 41, 786-803.

Gardner, R. C. (1985). Social Psychology and Second Language Learning. London, England: Edward Arnold.

Gardner, R. C., \& Symthe, P. C. (1975a). Second language acquisition: A psychological approach. Research Bulletin No 332, Department of Psychology, University of Western Ontario: London.

Hussein, G., Demirok, M. S., \& Uzunboylu, H. (2009). Undergraduate students' attitudes towards English language. Procedia- Social and Behavioral Sciences, 1, 431-433. http://dx.doi.org/10.1016/j.sbspro.2009.01.077

Jenkins, J., Cogo, A., \& Dewey, M. (2011). Review of developments in research in English as a lingua franca. Language Teaching, 44, 281-368. http://dx.doi.org/10.1017/S0261444811000115

Jones, W. R. (1950a). Attitudes towards Welsh as a second language: A further investigation. British Journal of Educational Psychology, 20, 117-132. http://dx.doi.org/10.1111/j.2044-8279.1950.tb01644.x

Kachru, B. B. (1985). Standard, codification, and sociolinguistic realism: The English language in the outer circle. In R. Quirk and H. G. Widdowson (Ed.), English in the World (pp. 11-30). Cambridge: Cambridge University Press.

Kaur, P. (2014). Attitudes towards English as a lingua franca. Procedia- Social and Behavioral Sciences, 118, 214-221. http://dx.doi.org/10.1016/j.sbspro.2014.02.029

Lee, H., \& Lee, K. (2013). Publish (in international indexed journals) or perish: Neoliberal ideology in a Korean university. Language Policy, 12(3), 215-230. http://dx.doi.org/10.1007/s10993-012-9267-2

Littlewood, W., \& Liu, N. (1996). Hong Kong Students and their English. Hong Kong: Macmillan.

Liu, M. (2007a). Chinese students' motivation to learn English at the tertiary level. Asian EFL Journal, 9, 126-146.

Liu, M., \& Zhao, S. (2011). Current language attitudes of mainland Chinese university students. Journal of Language Teaching and Research, (2)5, 963-968. http://dx.doi.org/10.4304/jltr.2.5.963-968

Liu, S., \& laohawiriyanon, C. (2013). Students' attitudes towards cultural learning in the English classroom: A case study of non-English major students in a Chinese university. International Journal of English Language Education, 3(1), 28-42. http://dx.doi.org/10.5296/ijele.v1i3.3508

Martin, P., Rey-Rocha, J., Burges, S., \& Moreno, A, I. (2014). Publishing research in English-language journals: Attitudes, strategies and difficulties of multilingual scholars of medicine. Journal of English for Academic Purposes, 16, 57-67. http://dx.doi.org/10.1016/j.jeap.2014.08.001

Matsuda, P. K. (2013). English only? Exploring the importance of academic writing across languages. Plenary lecture presented at the $7^{\text {th }}$ Conference of the European Association for the Teaching of the Academic Writing. Budapest, Hungary, 27-29..

Mcmillan, J. H., \& Schumacher, S. (2010). Research in Education: Evidence-Based Inquiry. (7th ed.), Pearson.

Ministry of Education of the People's Republic of China (2001). National Curriculum Standards for Teaching English as a Foreign Language in Elementary and Secondary Levels. Beijing, People's Education Press.

Mintzberg, H. (1979). An emerging strategy of "direct" research. Administrative Science Quarterly, 24, 580-589. http://dx.doi.org/10.2307/2392364

Noles, K. A., Pelletier, L., Clement, R., \& Vallerand, R. (2000). Why are you learning a second language? Motivational orientations and self-determination theory. Language Learning, 50, 57-85. http://dx.doi.org/10.1111/0023-8333.00111

Pierson, H. D. (1987). Language attitudes and language proficiency: A review of selected research. In Robert Lord \& Helen, N. L. Cheng (Ed.), Language Education in Hong Kong (pp. 51-82). Hong Kong: The Chinese University Press. 
Seidlhofer, B. (2004). Research perspectives on teaching English as a lingua franca. Annu. Rev. Appl. Linguistics, 24, 209-239. http://dx.doi.org/10.1017/S0267190504000145

Surur, S. R. (1981). Survey of students', teachers', administrators' attitudes towards English as a foreign English language in Saudi Arabian public school. (Unpublished doctoral dissertation). University of Kansas.

Sze-yen, L. (2005). Languages attitudes of Hong Kong students towards English, Cantonese, and Putonghua. Master's Thesis. Retrieved from the HKU libraries thesis online.

Tesser, A., \& Martin, L. (1996). The psychology of evaluation. In Higgins, E. T. \& Wruglanski, A. W. (eds.) Social Psychology: Handbook of Basic Principles (pp. 400-423). New York: Guilford Press.

Wu, W. (2006).Students' attitudes toward EMI: Using Chung Hua University as an example. Journal of Education and Foreign Language and Literature, 4, 67-84.

Wu, Y. (2012). On the English version of Chinese personal names. Perspectives: Studies in Translatology, 20(2), 139-140. http://dx.doi.org/10.1080/0907676X.2010.544746

Xu, W., Wang, Y., \& Case, R. E. (2010). Chinese attitudes towards varieties of English: A pre-Olympic examination. Language Awareness, 19(4), 249-260. http://dx.doi.org/10.1080/09658416.2010.508528

Yang, L., Liu, M., \& Wu, W. (2010). An investigation of Chinese undergraduate non-English majors' English Motivation. In Z. Lv, W. Zhang, \& P. Adams (Eds.), ELT at tertiary level in Asian context: issues and researches (pp. 48-62). Beijing: Tsinghua University.

Yin, R. K. (2003). Case Study Research: Design and Methods. Sage Publications, CA: USA.

Yu, Y. (2010). Attitudes of learners toward English: A case of Chinese college students. A Ph.D Dissertation, Ohio State University, USA.

Zhang, W., \& Ding, L. (2011). A preliminary study on Chinese EFL learners' attitudes towards their accent. Hong Kong, $17-21$.

Zheng, D., Young, M. F., Brewer, R. A., \& Wagner, M. (2009). Attitude and self-efficacy Change: English language learning in virtual worlds. CALICO Journal, 27(1), 205-231. http://dx.doi.org/10.11139/cj.27.1.205-231

This work is licensed under a Creative Commons Attribution 3.0 License. 